\title{
Synchrotron diffraction study of dissolution and precipitation kinetics of hydrides in Zircaloy-4
}

\author{
O. Zanellato a,b,*, M. Preuss ${ }^{\mathrm{c}}$, J.-Y. Buffiere ${ }^{\mathrm{b}}$, F. Ribeiro ${ }^{\mathrm{a}}$, A. Steuwer ${ }^{\mathrm{d}, \mathrm{e}}$, J. Desquines ${ }^{\mathrm{a}}$, \\ J. Andrieux ${ }^{\mathrm{f}}$, B. Krebs ${ }^{\mathrm{a}}$ \\ a Institut de Radioprotection et Sûreté Nucléaire, CEN Cadarache, 13115 St. Paul Les Durance, France \\ ${ }^{\mathrm{b}}$ INSA-Lyon, MATEIS CNRS UMR5510, F-69621 Villeurbanne, France \\ ' University of Manchester, Material Science Centre, Manchester M13 9PL, UK \\ ${ }^{\mathrm{d}}$ ESS AB, Stora Algatan 4, 22100 Lund, Sweden \\ e NMMU, Gardham Av., 6031 Port Elizabeth, South Africa \\ ${ }_{\mathrm{f}}^{\mathrm{I}}$ 15, European Synchrotron Radiation Facility, Grenoble, France
}

This paper presents observations of in situ heating and cooling cycles using synchrotron X-ray diffraction carried out on Zircaloy-4 plates charged to different levels of hydrogen content. The diffraction peak intensities were used to derive the weight fraction of hydrogen in solid solution and the solvi curves upon dissolution and precipitation. The heating and cooling rate did not seem to have a major influence on the solvi. Fast-cooling/dwell experiments showed that the precipitation kinetics are very fast. Finally the evolutions of the lattice strains from individual grain families were studied during dissolution and precipitation. The aim was to understand the role of interphase misfit stresses on the mechanisms of hydride formation and hysteresis between dissolution and precipitation. The results emphasise that changes in dissolved $\mathrm{H}$ concentration are responsible for a non-negligible part of the lattice distortion in the matrix, and that the diffraction strains must therefore be analysed with care.

\section{Introduction}

Core structural materials of water-cooled nuclear reactors, such as PWRs (Pressurised Water Reactors), are subject to a harsh environment (aqueous coolant, high neutron flux and moderately high temperatures) during service. Zirconium alloys have been used for decades as structural materials because of their combination of low neutron absorption cross-section and good mechanical and corrosion properties. Particularly zirconium alloys are used in fuel assemblies to encapsulate nuclear fuel. However, they have a strong affinity to hydrogen. In the reactor core, the material is exposed to irradiated and either boiling or pressurised water, which results in aqueous corrosion with some of the released hydrogen being picked up by the material. As a consequence, cladding tubes and other zirconium-based components typically contain hydrogen exceeding the solubility limit after sometime in service [1]. It is well established now that hydrogen precipitates (i.e. hydrides) embrittle the material [2] leading to reduced performances and to susceptibility to a phenomenon called delayed hydride cracking [3,4]. Diffusion of hydrogen is driven by concentration, temperature and stress

* Corresponding author. Address: CNAM, Laboratoire de Metallurgie, 2 rue Conte, 75003 Paris, France. Tel.: +33 158808809.

E-mail address: ozanellato@hotmail.fr (O. Zanellato). gradients: hydrogen tends to migrate towards lower concentrations, lower temperatures and/or regions of higher tensile stresses. Because of the steep temperature gradient through the wall thickness of the cladding tubes (fuel inside-water outside), hydrogen diffuses towards the outer surface of the tube that eventually leads to the formation of a hydride rim, and even blisters if the oxide spalls off [5], close to the outer surface. Additionally, an intentional or incidental temperature excursion of the fuel assembly can lead to an increased pick-up of hydrogen and consequently to an increased volume fraction of brittle hydrides upon cooling.

The structural integrity of fuel assemblies needs to be maintained both during service in the reactor as well as during handling and storage after service life. It is thus critical to understand the mechanisms behind hydrides precipitation and dissolution over wide temperature ranges and time scales.

Despite a large body of literature on this subject, there is still some controversy relating to the exact nature, stability and formation of hydrides on the microscopic and crystallographic level [6]. Although a large number of authors seems to have observed $\delta$ face centred cubic (fcc) hydrides $\left(\mathrm{ZrH}_{1.66}\right)$ as a stable phase [7], other results suggest the possibility of stabilising the $\gamma$ face centred tetragonal (fct) phase $(\mathrm{ZrH})$ [8]. Similarly, it has been largely assumed that $\mathrm{Zr}$ hydride precipitation is quasi instantaneous $[9,10]$, while other studies have suggested that there could be a 
non-negligible kinetics term which significantly delays hydride precipitation [11,12]. The kinetics argument has even resulted in the suggestion that the hysteresis of solubility limit universally observed between dissolution and precipitation of hydrides in zirconium is largely an out-of-equilibrium artefact resulting from slow precipitation [11]. It has also been suggested that the stabilisation of the $\gamma$ phase depends on the exact composition of the alloy with $\alpha$-stabilisers (such as $\mathrm{O}, \mathrm{Hf}$ and $\mathrm{Sn}$ ) and $\beta$-stabilisers (e.g. $\mathrm{Nb}$ ) respectively reducing and increasing the ability to form $\gamma$ hydrides [6].

Studying the kinetics of hydrides in $\mathrm{Zr}$ alloys is a difficult task because hydrogen cannot be kept in supersaturated solution by quenching according to MacEwen [13]. Thus conventional methods of quench-ageing cannot be applied. The experimental techniques used to date are mostly indirect observations (e.g. Differential Scanning Calorimetry) and thus leave room for debate. Consequently, most authors report only completion temperatures or terminal solubility temperatures (TSS), as a function of the total hydrogen content for a given sample. In addition, most analytical tools are surface or thin sample techniques (e.g. Transmission Electron Microscopy) where the stress state is significantly different from the bulk.

High-energy synchrotron X-ray diffraction is a very attractive technique to follow the dissolution and precipitation of hydrides since the high energy X-rays allow measurements deep within the material (several hundreds of microns at $80 \mathrm{keV}$ for zirconium) while the high flux available at modern synchrotron sources provides a very fast high resolution enabling the analysis of dynamic events [14]. In addition, advanced instrumentation at synchrotron $\mathrm{X}$-rays facilities are capable of providing significantly sharper reflections and lower background than conventional laboratorybased X-ray diffractometers can achieve. High flux and superior resolution enables phase fraction analysis, even of minor phases, with a high accuracy. However, unlike for neutrons, hydrogen is almost invisible to X-rays, and it should be noted here that in the context of zirconium hydrides, the scattering contribution from the hydrides is essentially that of the zirconium atoms bound in the hydride phase.

Two very recent publications have also focused on the study of hydrides dissolution and precipitation by synchrotron X-rays diffraction techniques $[15,16]$. This work differs from these papers in that it focuses on a more quantitative study of the evolution of the solid solution hydrogen content with temperature and attempts to establish a link with the evolution of the measured lattice strains in the matrix and the hydrides. Indeed the misfit stresses between the two phases are suggested to affect the hydride dissolution and precipitation [17]. The present paper also provides a more detailed analysis of the dissolution and precipitation kinetics.

\section{Experimental set-up}

\subsection{Sample preparation}

Two $400 \mu \mathrm{m}$ thick recrystallised Zircaloy- 4 sheet samples were studied. The plates were first hydrogen charged up to $475 \mathrm{ppm}$ (sample S1) and $600 \mathrm{ppm}$ (sample S2) in several passes at $450{ }^{\circ} \mathrm{C}$ under $\mathrm{H}_{2}$ gas at École Centrale de Paris, France. Hydrogen contents were verified by hot extraction at several points in the plates and the results showed no significant content gradients (approximately $3 \mathrm{ppm} / \mathrm{mm}$ on average). Thus no further homogenisation treatment was performed. The matrix grains were equiaxed with an average diameter of approximately $10 \mu \mathrm{m}$. The texture measured by EBSD prior and after charging showed a strong basal texture typical of recrystallised plate material [18]. Hydrogen charging did not affect the texture significantly.

\subsection{Synchrotron X-ray diffraction setup}

The diffraction experiments were performed on beam line ID15B at the European Synchrotron Radiation Facility (ESRF), Grenoble, France. Samples with the dimensions of $20 \times 20 \times 0.4 \mathrm{~mm}^{3}$ were mounted on a commercial Linkam THMSG 600 variable temperature stage which consists of a silver block heating element in a sealable chamber. The samples were maintained in good thermal contact with the conductive heating plate by a spring and a reflective glass piece. To prevent significant oxidation, the heat treatments were performed under an inert gas flow (Argon). The temperature was recorded by a thermocouple built into the heating plate. Given the small thickness of the sample the heating plate temperature is considered as representative of the sample temperature. The temperature stage was set-up to undertake diffraction experiments in a transmission configuration [19] with a beam size of $1 \times 1 \mathrm{~mm}^{2}$ at a wavelength $\lambda=0.143 \AA$ $(E=86.7 \mathrm{keV})$. The sample was positioned on the Linkam temperature stage with the normal direction of the plate (ND) being parallel to the incident beam. Debye-Scherrer rings were recorded by a planar 2D detector (Pixium 4700, Thales Electron Devices, 38430 Moiron, France) with $1910 \times 2480$ pixels [20] placed at a distance of $1265 \mathrm{~mm}$ from the sample.

\subsection{Thermal cycles}

Sample S1 was subjected to seven successive cycles each consisting of a heating and a cooling phase with the same constant rate and a dwell time of $30 \mathrm{~min}$ at maximum temperature $T_{\max }$. Sample S2 underwent five similar cycles except the last two, which had an additional dwell at $400{ }^{\circ} \mathrm{C}$ during cooling instead of direct cooling to room temperature. The sequence of cycles for S1 and S2 are given in Fig. 1. Due to beam loss during the experiment the fourth cycle on S1 was repeated twice.

Cooling rates not exceeding $10^{\circ} \mathrm{C} / \mathrm{min}$ could be maintained close to room temperature while this was not possible for faster cooling rates. Cooling rates of $20^{\circ} \mathrm{C} / \mathrm{min}, 50^{\circ} \mathrm{C} / \mathrm{min}$ and $100^{\circ} \mathrm{C} /$ min could only be maintained down to temperatures of $140^{\circ} \mathrm{C}$, $230^{\circ} \mathrm{C}$ and $320^{\circ} \mathrm{C}$, respectively.

The acquisition times of the diffraction signal varied between 10 and 40s, according to the cooling rates used.

\subsection{Data analysis}

The diffraction rings in a polycrystalline bulk material tend to have a not perfectly circular shape due to intergranular elastic strains. Moreover, the intensity profile along a diffraction ring is a function of the polarisation of the beam and is maximum along a direction corresponding to RD. A full ring integration can thus introduce artificial peak broadening. As a consequence, the $2 \mathrm{D}$ diffraction patterns were azimuthally integrated for $Q$ vectors at $\pm 10^{\circ}$ along the transverse direction (TD) of the measured sheet material. The advantage of a partial integration is that less artificial peak broadening is introduced, which provides an improvement in $2 \theta$ resolution while maintaining good counting statistics.

In order to account for the effect of beam decay and refills, the spectra were normalised by the incoming intensity. Typical diffraction spectra are presented in Fig. 2 for sample S1. At $40^{\circ} \mathrm{C}$, the peaks corresponding to the hcp $\alpha$ - $\mathrm{Zr}$ matrix and the fcc $\delta$ hydrides can be clearly identified. Additional peaks are also visible, especially around $2.15 \AA$. These seem to belong to a C15 structure of $\mathrm{Zr}(\mathrm{Fe}, \mathrm{Cr})_{2}$ precipitates also referred to as SPP (second phase particles) in $\mathrm{Zr}$ alloys $[21,22]$. At $550^{\circ} \mathrm{C}$, only the matrix and SPP reflections remain while the hydride peaks have disappeared indicating full dissolution of the hydride phase. No other hydride phases were identified in the spectra at any stage of the experiments. 

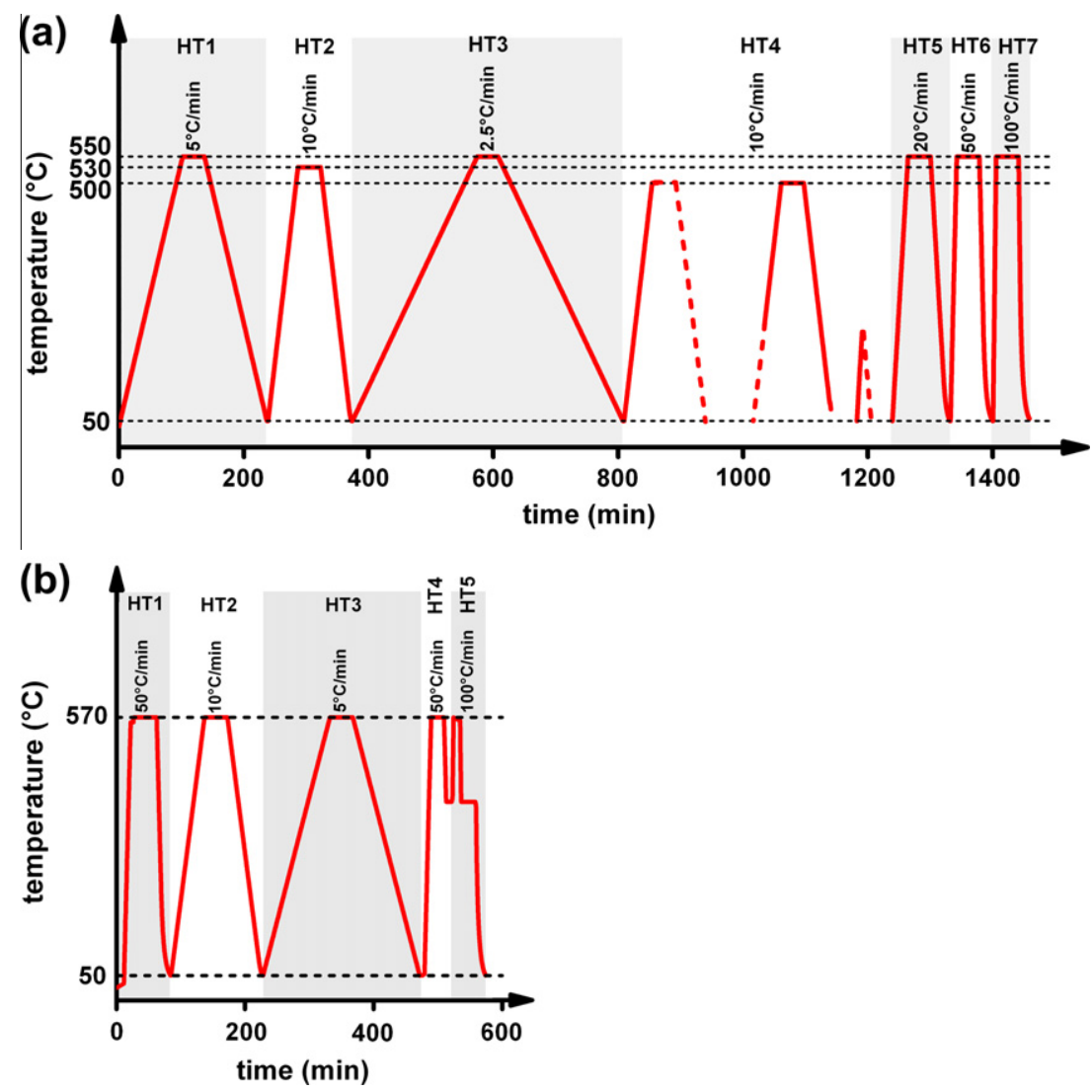

Fig. 1. Heat treatments performed on (a) S1 and (b) S2. The dotted lines correspond to a loss of recording due to beam loss.

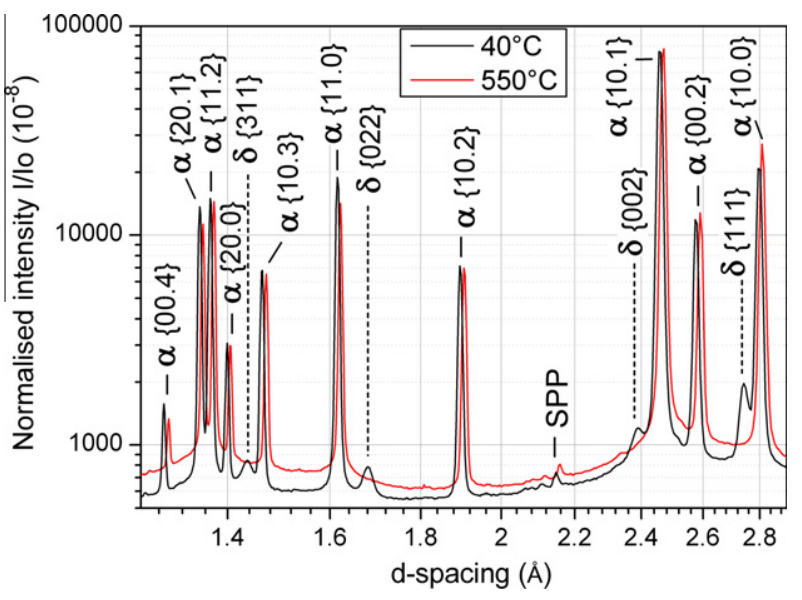

Fig. 2. Typical azimuthally integrated diffraction spectra over $\mathrm{a} \pm 10^{\circ}$ wedge around the transverse direction at $40^{\circ} \mathrm{C}$ and $500{ }^{\circ} \mathrm{C}$. Intensities are plotted in a log scale in order to emphasise the peaks with lower intensities. The peaks marked SPP correspond to $\mathrm{Zr}(\mathrm{Fe}, \mathrm{Cr})_{2}$. At high temperature, the hydride peaks have disappeared indicating full dissolution of the hydride phase.

In order to fit the data, the TOPAS software package was used [12]. The peak shape selected was pseudo-Voigt, which is a weighted convolution of Gaussian and Lorentzian functions. The matrix peaks, which are relatively intense compared to the hydride reflections, were fitted individually via single peak fits. The weak hydride peaks required the use of some constraints on the peak positions in order to have a more convergent refinement: the $h k l$ function was used, where the individual intensities are free to vary but the positions are deduced from the refinable lattice parameter $a$ of the fcc cell [23].
The normalised integrated intensities of the diffraction peaks depend on the diffracting plane family $\{h k l\}$, the temperature and the diffracting volume. The latter is itself a function of the phase fractions and texture. The intensity of reflection $\{h k l\}$ can be written as

$I_{h k l}(T)=I_{0} \cdot K \cdot f_{\delta}(T) \cdot F_{\mathrm{r}} \cdot \exp (-2 W)$

where $I_{0}$ is the incoming intensity, $F_{\mathrm{r}}$ represents the rigid lattice contribution to the structure factor (a constant with regards to the temperature), $K$ a factor accounting for texture, $f_{\delta}$ the volume fraction of hydride (independent of the reflection considered) and $\exp (-2 W)$ the Debye-Waller factor which characterises the temperature contribution to the peak intensities [24].

Since the materials tested here were in a recrystallised condition, it can be expected that the zirconium phase displays a stable texture when heat-treated below the $\alpha+\beta$ transus [18]. This was confirmed by EBSD texture analyses of the matrix phase performed prior and after the heat treatments which showed little variation. Regarding the hydrides, the peak intensities measured at $50{ }^{\circ} \mathrm{C}$ before and after each thermal cycle did not vary more than a few percent (typically less than 10\%) indicating that the texture changes are also negligible (this is also a good indication that there was no hydrogen desorption). Furthermore the $\delta-\{311\}$ reflection, which was used for computing phase fractions, has a high multiplicity (equal to 24).

Consequently, its intensity is less sensitive to texture changes. Thus we will consider the $K$ factor in Eq. (1) as constant with temperature.

For a given reflection $\{h k l\}$ with a $d$-spacing $d$, the Debye-Waller factor can be expressed as:

$\exp \left(-B(T) / 2 d^{2}\right)$ 
where $B$ accounts for the amplitude of atomic vibrations.

The ratio of intensity of two reflections $\{h k l\}$ and $\left\{h^{\prime} k^{\prime} l^{\prime}\right\}$ at a given temperature $T$ can thus be written as:

$I_{h k l}(T) / I_{\mathrm{h}^{\prime} k^{\prime} l^{\prime}}(T)=A \cdot \exp \left[-B(T)\left(1 / 2 d^{2}-1 / 2 d^{\prime 2}\right)\right]$

where $A$ is constant with temperature. Using this relationship, the evolution of $B \ln (A)$ with temperature $T$ was deduced from the intensity fit of three hydride peaks in the experimental spectra. Since the ratios measured for several reflections did not show any trend with temperature, the Debye Waller contribution was considered negligible in this work.

As a result of these assumptions, any changes in intensities only reflect changes in volume phase fractions.

In addition, it is assumed that the solubility limit of hydrogen in zirconium at $50{ }^{\circ} \mathrm{C}$ is $0 \mathrm{ppm}$, which is in close agreement with values reported in the open literature (see [25] for example). Consequently, the initial peak intensity represents the volume fraction of hydrides deduced from the total hydrogen content in the material. Using a linear relationship between peak intensity and volume fraction of hydride, the volume fraction of hydride $f_{\delta}^{v}$ can be expressed at any given temperature as:

$f_{\delta}^{\mathrm{v}}(T)=\frac{I(T)}{I\left(50^{\circ} \mathrm{C}\right)} \times f_{\delta}^{\mathrm{v}}\left(50^{\circ} \mathrm{C}\right)$

where $I$ is the normalised peak intensity. The volume fraction of hydrides at $50{ }^{\circ} \mathrm{C} f_{\delta}^{\vee}\left(50{ }^{\circ} \mathrm{C}\right) \approx 3 \%$ and $3.8 \%$ for samples S1 and S2 respectively.

From the lever rule (conservation of matter), one can express the hydrogen content in solid solution at a temperature $T$ as:

$[\mathrm{H}]=\frac{[\mathrm{H}]^{\mathrm{tot}}-f_{\delta}^{\mathrm{at}}[\mathrm{H}]^{\delta}}{\left(1-f_{\delta}^{\mathrm{at}}\right)}$

where $[\mathrm{H}]^{\text {tot }}$ and $[\mathrm{H}]^{\delta}$ are the hydrogen contents in total and in the $\delta$ phase respectively, and $f_{\delta}^{a t}$ the atomic fraction of $\delta$ phase. The stoichiometry of the $\delta$ phase as a function of temperature was derived from Ref. [1] in order to compute $[\mathrm{H}]^{\delta}$.

The relationship between $f_{\delta}^{\text {at }}$ and $f_{\delta}^{v}$ leads to:

$[\mathrm{H}]=\frac{[\mathrm{H}]^{\mathrm{tot}}+k}{k}$

with

$k=\frac{2\left([\mathrm{H}]^{\mathrm{tot}}-[\mathrm{H}]^{\delta}\right) f_{\delta}^{v} v_{\alpha}}{\left(1-f_{\delta}^{\mathrm{v}}\right)\left(1-[\mathrm{H}]^{\delta}\right) v_{\delta}}$

where $v_{\alpha} \approx 46.6 \AA^{3}$ and $v_{\delta} \approx 108.5 \AA^{3}$ are the volumes of the $\alpha$ and $\delta$ lattice cells respectively, derived from the lattice parameters given by Singh et al. [35].

\section{Results}

\subsection{Hydride dissolution and precipitation}

The calculation of the hydrogen content in solid solution $[\mathrm{H}]$ was based on the intensities of the $\delta$-\{311\} reflection since this reflection has a high multiplicity and provided the best fit and the least overlap with $\mathrm{Zr}$ matrix peaks. The evolution of $[\mathrm{H}]$ with temperature for sample S1 (475 ppm) during heat treatment HT1 $\left(5^{\circ} \mathrm{C} / \mathrm{min}\right)$ is plotted in Fig. 3, based on the peak intensities recorded in the RD and TD direction of the zirconium plate. The good agreement between both directions demonstrates that no texture change can have occurred during the temperature excursion. In the rest of the paper only the data in the TD direction will be presented. In Fig. 4, the evolution of $[\mathrm{H}]$ in the matrix is plotted in logarithmic scale as a function of the reciprocal temperature. Fig. 4a shows the $[\mathrm{H}]$ evolution for S1 and S2 when applying a heating/

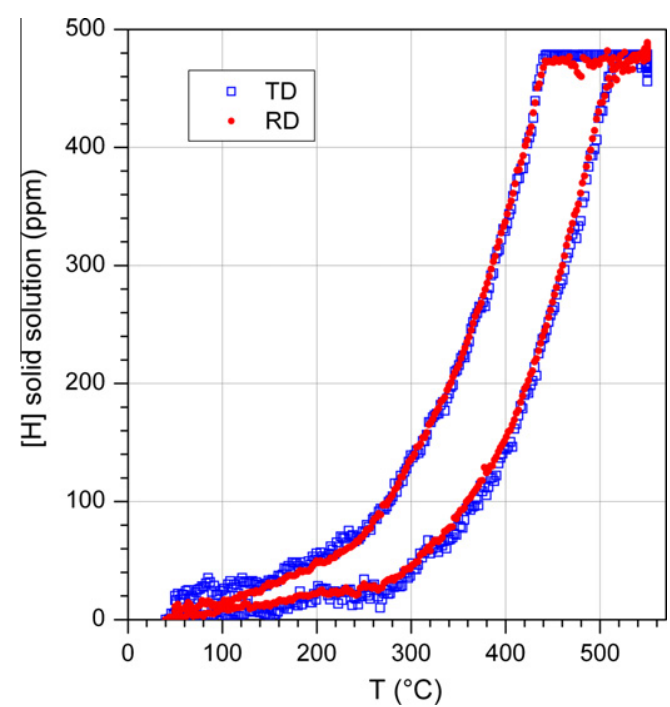

Fig. 3. Evolution of hydrogen content based on the $\{311\}_{\delta}$ peak intensity along TD and RD in sample S1 (475 ppm) during heat treatment HT1 $\left(5^{\circ} \mathrm{C} / \mathrm{min}\right)$.

cooling rate of $5^{\circ} \mathrm{C} / \mathrm{min}$. Excellent agreement was observed when comparing the $[\mathrm{H}]$ evolution between the two samples providing great confidence in the experimental methodology. The dissolution and precipitation temperatures (TSS) correspond to the temperatures of peak extinction and reappearance. These points are thus very reliable data points since they do not derive from any computation. For S1 (containing $475 \mathrm{ppm} \mathrm{H}$ ) and with a rate of $5{ }^{\circ} \mathrm{C} / \mathrm{min}$, these temperatures are $520^{\circ} \mathrm{C}$ and $442{ }^{\circ} \mathrm{C}$ during heating and cooling respectively. On the other hand, the hydrogen content in solid solution in S2 is equal to $475 \mathrm{ppm}$ for temperatures of approximately $510^{\circ} \mathrm{C}$ and $441^{\circ} \mathrm{C}$ upon heating and cooling respectively (at $5^{\circ} \mathrm{C} / \mathrm{min}$ ). The TSS points for $\mathrm{S} 1$ lie thus very close to the derived solvi lines for S2 (as is also clear on Fig. 4) which is an indicator that the analysis is valid. The TSS temperatures for both samples are reported in Table 1 along with values derived from the solvi laws established in the literature. The hysteresis classically observed between hydride precipitation and dissolution in $\mathrm{Zr}$ alloys is also clearly visible: upon cooling, the solubility limit is shifted towards lower temperatures. During heating and cooling, the plotted $[\mathrm{H}]$ curves appear linear in the high temperature region (above approximately $240-270^{\circ} \mathrm{C}$ ) indicating a classical exponential behaviour that can be written as:

$[\mathrm{H}]=A \times \exp (-Q / R T)$

with $[\mathrm{H}]$ and $A$ in weight ppm, $Q$ in $\mathrm{J} \mathrm{mol}^{-1}, R=8.314 \mathrm{~J} \mathrm{~mol}^{-1} \mathrm{~K}^{-1}$ and $T$ the temperature in $\mathrm{K}$.

Table 1 compares the pre-exponential and exponential terms $A$ and $Q$ obtained from the least-square based line fitting of the data in the given temperature ranges and $A$ and $Q$ found in literatures [10,25-28].

It can be seen that the precipitation behaviour observed by high-energy synchrotron X-ray diffraction is in good agreement with literature values. On the other hand, the pre-exponential factor and the activation energy for dissolution measured by synchrotron X-rays are substantially higher than values reported in the literature. Since the DSC peaks are much broader during heating than during cooling (as explained in [26]), the error in the determination of TSSd is larger which could explain some of the discrepancies.

As evidenced by the change of slope, the solubility laws inferred from the high temperature exponential behaviour do not apply at lower temperatures. A change of regime in TSS data has been 
(a)

$\mathrm{T}\left({ }^{\circ} \mathrm{C}\right)$

$\begin{array}{llllllllll}560 & 441 & 352 & 283 & 227 & 182 & 144 & 112 & 84 & 60\end{array}$

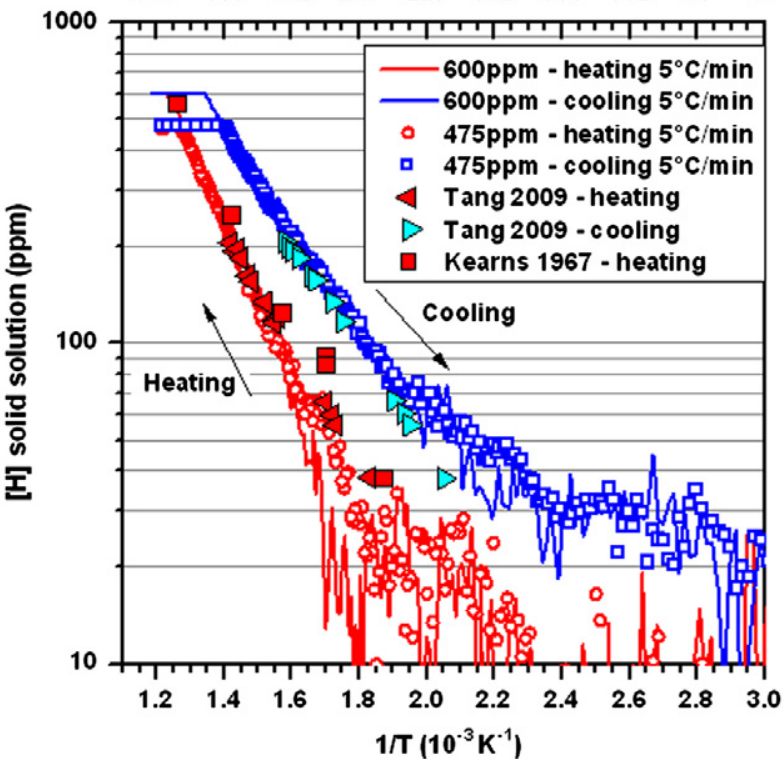

(b)

$\mathbf{T}\left({ }^{\circ} \mathrm{C}\right)$

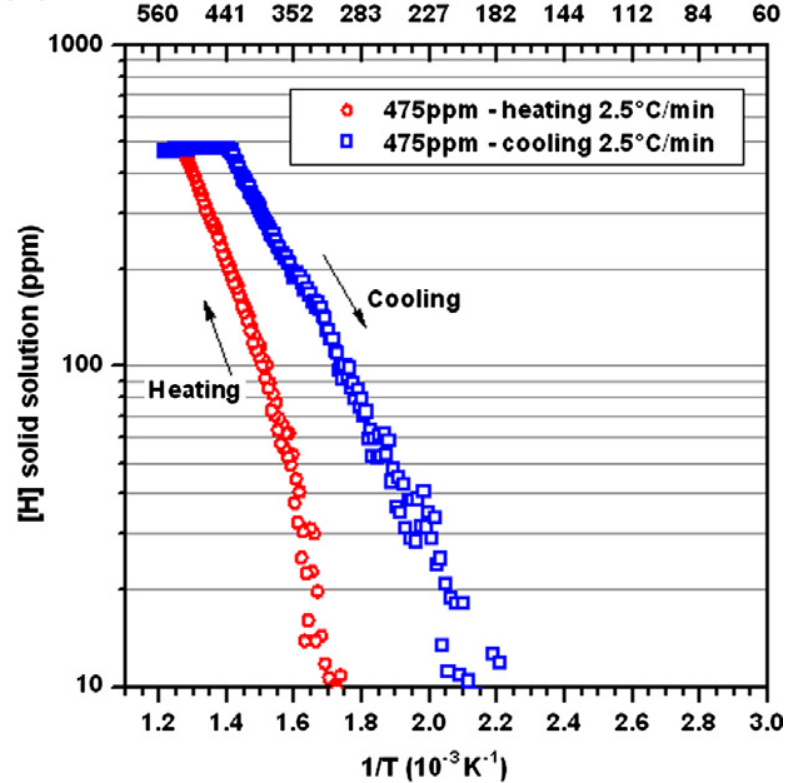

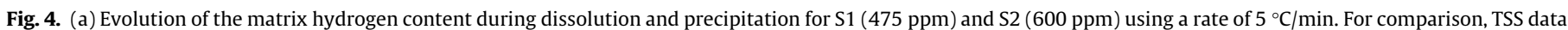

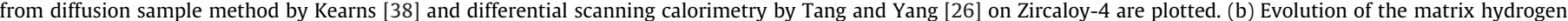
content during dissolution and precipitation for $\mathrm{S} 1$ for a rate of $2.5^{\circ} \mathrm{C} / \mathrm{min}$.

Table 1

Fitted and literature parameters for the precipitation and dissolution solubility laws.

\begin{tabular}{|c|c|c|c|c|c|c|c|c|c|c|c|}
\hline & \multirow[t]{2}{*}{ Material } & \multirow[t]{2}{*}{ Technique } & \multirow{2}{*}{$\begin{array}{l}{[\mathrm{H}]} \\
\text { range } \\
(\mathrm{ppm})\end{array}$} & \multirow{2}{*}{$\begin{array}{l}\text { Max } \\
\text { temp. } \\
\left({ }^{\circ} \mathrm{C}\right)\end{array}$} & \multirow{2}{*}{$\begin{array}{l}\text { Heating/ } \\
\text { cooling rates } \\
\left({ }^{\circ} \mathrm{C} / \mathrm{min}\right)\end{array}$} & \multirow{2}{*}{$\begin{array}{l}\text { TSSd/TSSp temp. } \\
\left({ }^{\circ} \mathrm{C} /{ }^{\circ} \mathrm{C}\right) \text { at } \\
475 \mathrm{ppm}\end{array}$} & \multirow{2}{*}{$\begin{array}{l}\text { TSSd/TSSp temp. } \\
\left({ }^{\circ} \mathrm{C} /{ }^{\circ} \mathrm{C}\right) \text { at } \\
600 \mathrm{ppm}\end{array}$} & \multicolumn{2}{|c|}{ Dissolution } & \multicolumn{2}{|c|}{ Precipitation } \\
\hline & & & & & & & & $A(\mathrm{ppm})$ & $Q\left(\mathrm{~J} \mathrm{~mol}^{-1}\right)$ & $A(\mathrm{ppm})$ & $Q\left(\mathrm{~J} \mathrm{~mol}^{-1}\right)$ \\
\hline $\begin{array}{l}\text { Present } \\
\text { study }\end{array}$ & $\mathrm{Zr}-4$ & DRX & $\begin{array}{l}\text { Up to } \\
600\end{array}$ & 570 & 5 & $520 / 442$ & $540 / 477$ & 510,800 & $45,610 \pm 300$ & 66,440 & $29,630 \pm 160$ \\
\hline $\begin{array}{c}\text { Slattery } \\
1967 \\
{[28]}\end{array}$ & $\mathrm{Zr}-2$ & Dilatometry & $25-250$ & 500 & 1.5 & $539 / 482^{a}$ & $579 / 524^{a}$ & $96280^{\mathrm{b}}$ & $34930^{\mathrm{b}}$ & $89500^{\mathrm{b}}$ & $31230^{\mathrm{b}}$ \\
\hline $\begin{array}{c}\text { McMinn } \\
2000 \\
{[25]}\end{array}$ & $\begin{array}{l}\mathrm{Zr}-2 / \mathrm{Zr}- \\
4\end{array}$ & DSC & $20-80$ & 400 & 2 & $527 / 457^{a}$ & $562 / 488^{a}$ & 106,447 & 35,991 & 138,746 & 34,469 \\
\hline $\begin{array}{l}\text { Une } \\
\qquad 2003 \\
{[10]}\end{array}$ & $\begin{array}{l}\text { Zr-2/ } \\
\text { High Fe } \\
\text { Zry }\end{array}$ & DSC & $40-542$ & 600 & 10 & $512 / 444^{\mathrm{a}}$ & $546 / 481^{a}$ & 128,000 & 36,540 & 52,600 & 28,068 \\
\hline $\begin{array}{l}\text { Une } \\
\qquad 2004 \\
{[27]}\end{array}$ & Pure $\mathrm{Zr}$ & DSC & $9-281$ & 500 & 10 & $532 / 496^{a}$ & $566 / 541^{a}$ & 141,000 & 38,104 & 33,900 & 27,291 \\
\hline $\begin{array}{l}\text { Tang } \\
\qquad 2009 \\
{[26]}\end{array}$ & $\mathrm{Zr}-4$ & DSC & $20-240$ & 500 & 10 & $548 / 468^{a}$ & $591 / 509^{a}$ & 52,575 & 32,117 & 40,135 & 27,336 \\
\hline
\end{tabular}

a Derived from the solubility laws.

b Refinement performed on the experimental data in the paper.

previously reported during precipitation but not dissolution $[10,25]$. A proposed explanation for the change of slope was a possible precipitation of $\gamma$ hydrides at low temperature resulting in a change of temperature dependent solubility. However, the diffraction spectra recorded at low temperatures do not show any evidence of a tetragonal $\gamma$ hydride structure to support this hypothesis. This non-uniform behaviour over the whole range of temperature can also explain some of the discrepancy observed in Table 1: some studies have been performed at low hydrogen content [25-28] and the low temperature behaviour may strongly bias the fitted model.

The change of slope is not visible with a slower heating and cooling rate of $2.5^{\circ} \mathrm{C} / \mathrm{min}$ (Fig. 4b). A problem of kinetics, possibly related to misfit strains becoming an important aspect at lower temperatures when the metal matrix is stronger (less ductile), could thus explain the low temperature phenomenon observed with a rate of $5{ }^{\circ} \mathrm{C} / \mathrm{min}$.

\subsection{Effect of heating/cooling rate}

Fig. 5 displays the change of $[\mathrm{H}]$ as a function of temperature in the high temperature region and for six of the performed heat treatments on S1. It can be seen that nucleation of hydrides is slightly delayed when applying cooling rates larger than $10^{\circ} \mathrm{C} / \mathrm{min}$. Considering that the temperature was recorded by a thermocouple on the heating plate of the furnace rather than on the sample itself, the 


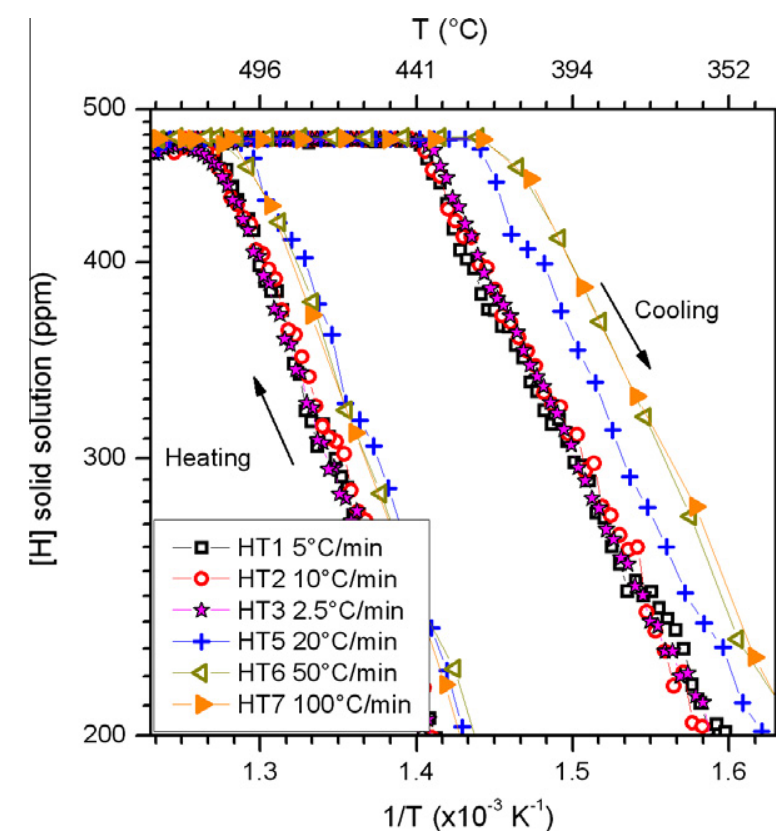

Fig. 5. Hydrogen content evolution in the high temperature range for six of the heat treatments on S1. Errors from peak fitting are typically of $\pm 5 \mathrm{ppm}$.

observed delay might be slightly overestimated. The effect of cooling rates on dissolution and precipitation of hydrides seems to be very small as also observed by Colas et al. [15].

Fig. 6 plots the terminal solubility temperatures (TSS) for dissolution and precipitation as a function of heating/cooling rate for sample S1. The TSSd and TSSp values were determined by identifying the intercept of the horizontal line response of $[\mathrm{H}]$ above the solubility limit with the linear line response during heating/cooling in Fig. 5. Fig. 6 demonstrates that the TSSd values are only slightly affected by the heating rate showing decreased TSSd values with increasing heating rate. This slight trend cannot be explained at this stage. The TSSp values first stay constant with increasing cooling

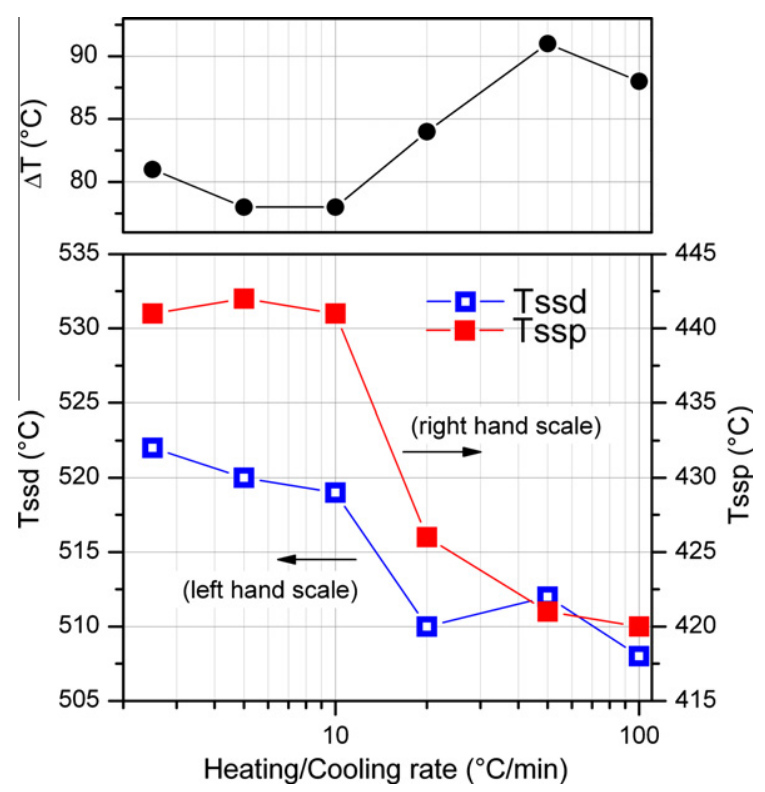

Fig. 6. Terminal solubility temperatures upon dissolution and precipitation (right and left axes respectively), and differential temperature as a function of the heating and cooling rates. rate, which is in good agreement with the experimental results of McMinn who focused on the range $0.5-10^{\circ} \mathrm{C} / \mathrm{min}$ [25]. Above $10^{\circ} \mathrm{C} / \mathrm{min}$, the TSSp values decrease more rapidly indicating an increased difficulty for hydride nucleation. The temperature range $\Delta T$ between TSSd and TSSp varies between $80^{\circ} \mathrm{C}$ for low heating/cooling rates and $90^{\circ} \mathrm{C}$ for high heating/cooling rates. The indexes for the magnitude of hysteresis of hydrogen solubility $\Delta T / \mathrm{TSSp}(\mathrm{K})$ range from 0.11 to 0.13 which is consistent with values reported in [26] at those temperatures.

As mentioned previously, it must be kept in mind that the temperature is not measured on the sample directly but on the heating stage. This is likely to introduce some error in the measurement especially for higher rates. The results presented on Fig. 6 must thus be considered with care.

\subsection{Effect of $400^{\circ} \mathrm{C}$ hold temperature}

The effect of rapidly cooling a sample from above the solubility limit to a relatively high hold-temperature was studied with sample S2 during heat treatments HT4 and HT5. The sample was cooled from $570{ }^{\circ} \mathrm{C}$ at rates of $50^{\circ} \mathrm{C} / \mathrm{min}$ and $100{ }^{\circ} \mathrm{C} / \mathrm{min}$ to $400{ }^{\circ} \mathrm{C}$ while diffraction spectra were collected every $8 \mathrm{~s}$ for $8 \mathrm{~min}$ and $20 \mathrm{~min}$ respectively. The evolution of the solid solution hydrogen content, inferred from the $\delta$ - $\{311\}$ peak intensities is plotted versus dwell time in Fig. 7. During the dwell time, the amount of hydrogen in solid solution reduces from approximately $400 \mathrm{ppm}$ to $300 \mathrm{ppm}$. By comparison, only $160 \mathrm{ppm}$ of hydrogen is in solution at $400^{\circ} \mathrm{C}$ when the material is heated up slowly. In both cases, it seems to take approximately 240 s to stabilise the hydrogen content at $300 \mathrm{ppm}$. The average rate of precipitation at $400{ }^{\circ} \mathrm{C}$ is about $1.25 \mathrm{ppm} / \mathrm{s}$, which is in good agreement with precipitation rates of $2 \mathrm{ppm} / \mathrm{s}$ reported for the same dwell temperature in $[10,26]$ where differential scanning calorimetry peak width analysis was used.
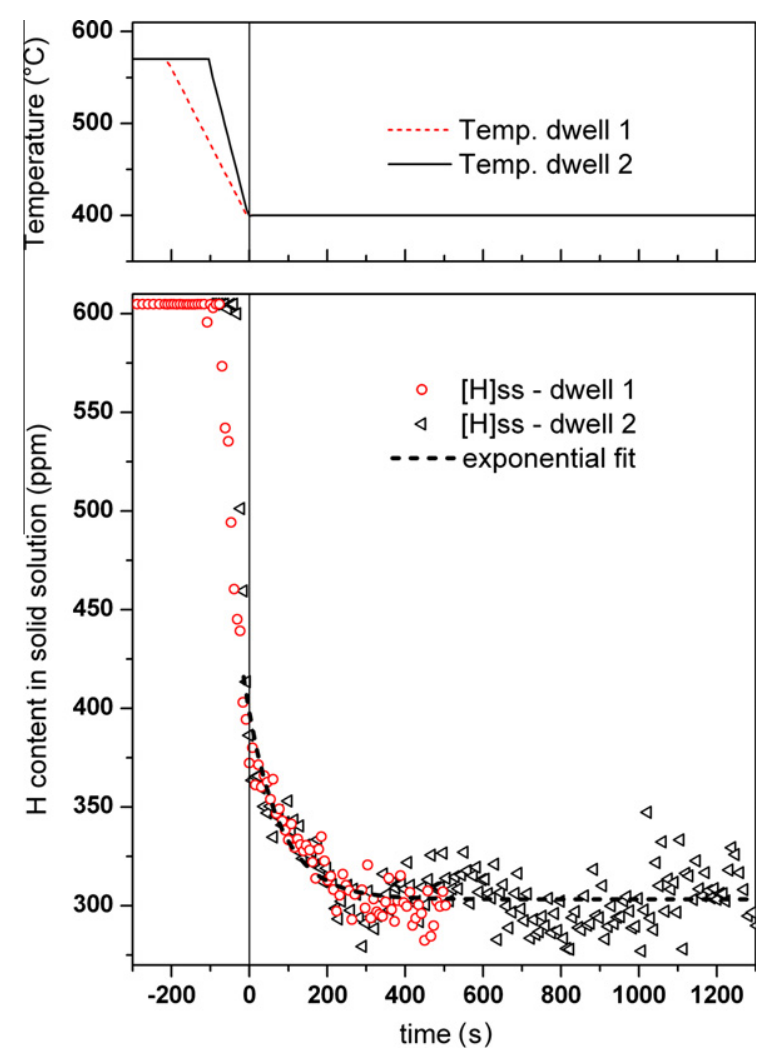

Fig. 7. Evolution of the hydrogen content in solid solution during a dwell at $400{ }^{\circ} \mathrm{C}$ on sample S2 (600 ppm). 
(a)

$\mathrm{T}\left({ }^{\circ} \mathrm{C}\right)$
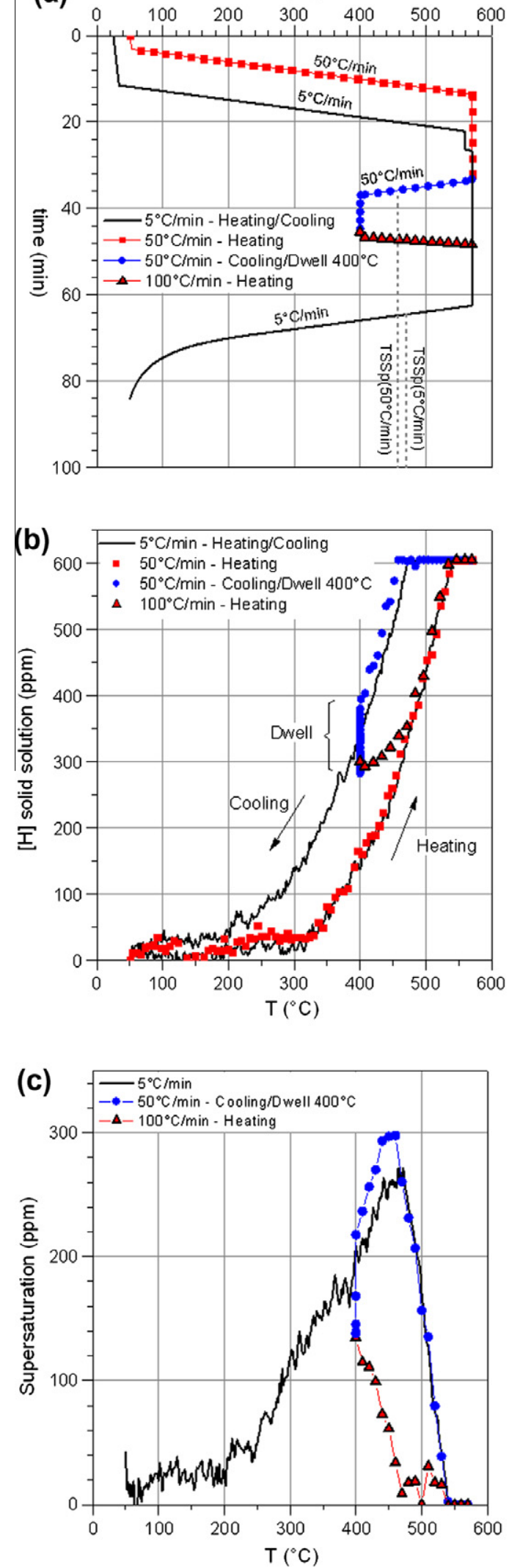

(d) $\mathrm{T}\left({ }^{\circ} \mathrm{C}\right)$

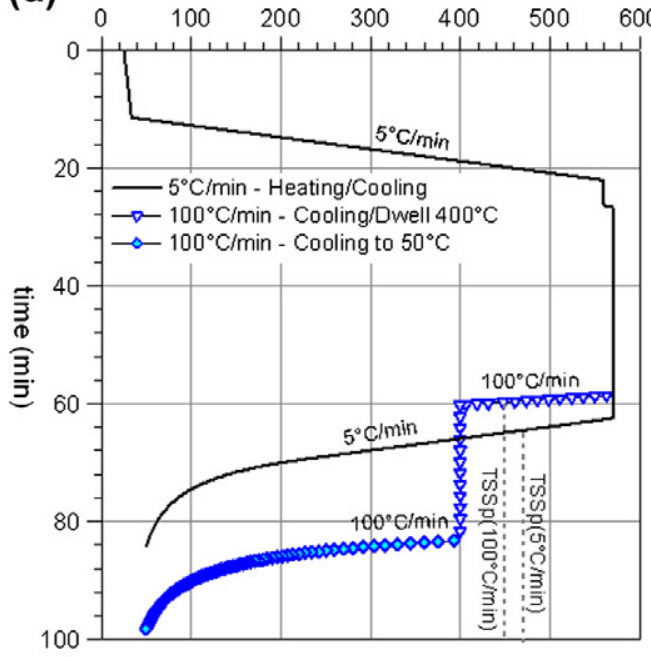

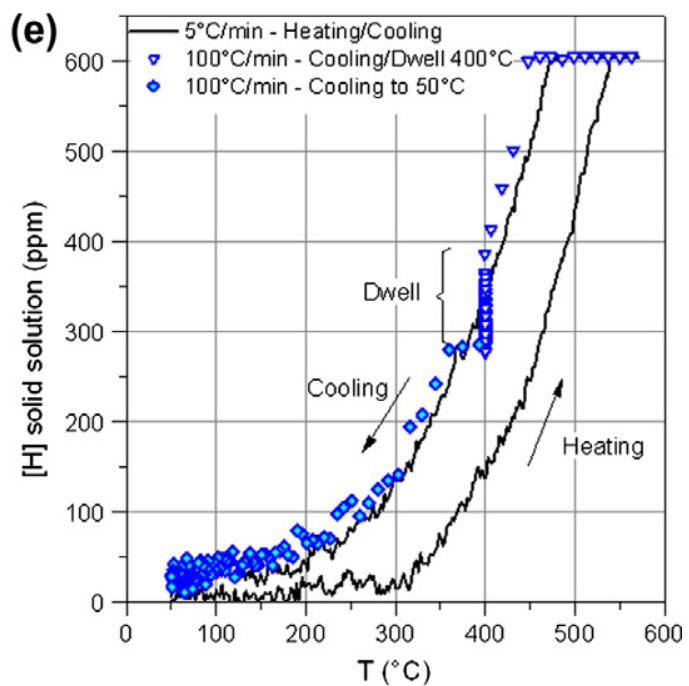

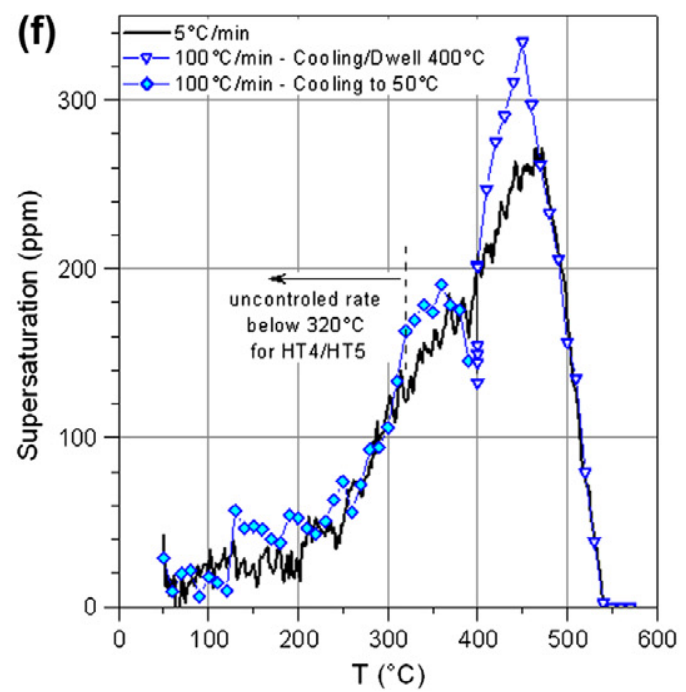

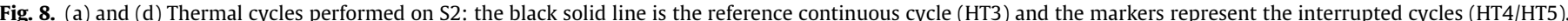

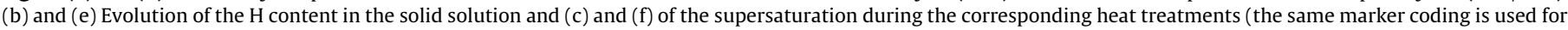
all subplots to identify the various stages). 

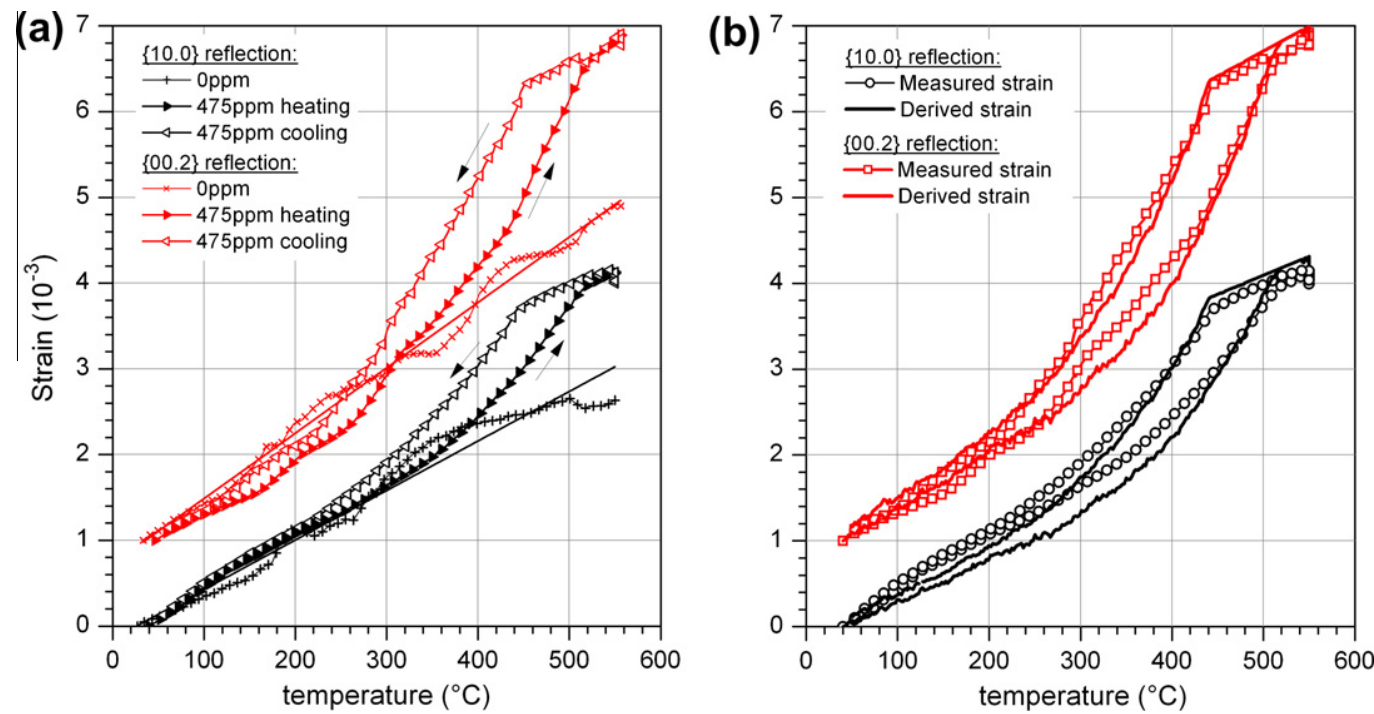

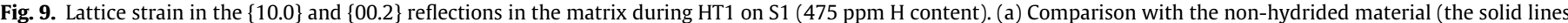

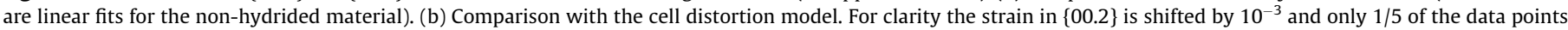
are plotted.

Based on the diffusion model proposed by Kammenzind et al. [29], the evolution of the average $\mathrm{H}$ content in solid solution during a dwell following quenching can be described as:

$[\mathrm{H}](t)=[\mathrm{H}]^{0}+\left([\mathrm{H}]^{\infty}-[\mathrm{H}]^{0}\right) \times \exp \left(-\alpha^{2}(T) \times t\right)$

with $[\mathrm{H}]^{0}=600 \mathrm{ppm}$ the content before quenching, $[\mathrm{H}]^{\infty}$ the steady state concentration and $\alpha(T)$ a characteristic constant. The fit to the experimental data in Fig. 7 was obtained for $\alpha^{2}=0.012 \mathrm{~s}^{-1}$ and $[\mathrm{H}]^{\infty}=303 \mathrm{ppm}$. The characteristic time for precipitation at $400{ }^{\circ} \mathrm{C}$ is thus $1 / \alpha^{2}=83 \mathrm{~s}$.

Fig. 8 shows a comparison between the HT3 (continuous at $5{ }^{\circ} \mathrm{C} / \mathrm{min}$ ) and HT4/HT5 cycles, for which there was a temperature hold at $400{ }^{\circ} \mathrm{C}$. As for sample S1, upon heating, both solubility lines are very close (black line and red square markers) confirming the negligible kinetics term upon dissolution. As observed previously this is no longer true during cooling: the difference in cooling rates and the non-negligible kinetics term upon precipitation induce a different TSSp. This can be translated into a higher supersaturation peak with the higher rates (see Fig. $8 \mathrm{c}$ and $\mathrm{f}$ ). The supersaturation is calculated at a given temperature $T$ as the difference of hydrogen contents between the current state of the heat treatment and the initial continuous heating. At the end of the dwells at $400{ }^{\circ} \mathrm{C}$ for HT4/HT5, the H content is lower than for HT3 with a continuous cooling rate of $5{ }^{\circ} \mathrm{C} / \mathrm{min}$. It indicates that even a rate of $5^{\circ} \mathrm{C} / \mathrm{min}$ is too fast to maintain equilibrium during continuous cooling. After the dwells the solid solution is still highly supersaturated by approximately $140 \mathrm{ppm}$ compared to the dissolution solubility at $400{ }^{\circ} \mathrm{C}$. After the second dwell, upon cooling down to room temperature, the hydrogen content stays constant for approximately $50{ }^{\circ} \mathrm{C}$ resulting in an increase of supersaturation. The supersaturation upon further cooling on HT4/HT5 stays higher than for cooling on HT3. At $320^{\circ} \mathrm{C}$ the supersaturation drops for HT4/HT5 and is very well correlated to the reduction in cooling rate due to the lack of rate control below that temperature.

\subsection{Lattice strains in the matrix}

The relative shifts in diffraction peak positions were used to derive the amount of reflection specific lattice strain experienced during the thermal processes. These lattice strains are plotted on Fig. 9 for the $\{10.0\}$ and $\{00.2\}$ matrix reflections along TD. These particular reflections define the upper and lower bound of the anisotropic elastic behaviour of an hcp cell [30]. Fig. 9a compares the strain gained during the thermal cycle HT1 on S1 and a heating/cooling cycle on the non-hydrided base material. Since upon heating and cooling the strains in the base material showed a similar trend only the heating part is represented here for clarity. It should be noted that no absolute strains are plotted since the anisotropic thermal expansion in $\mathrm{Zr}$ results in significant thermally induced intergranular stresses [31]. The strain evolution in the base material is relatively linear with temperature in the measured range, indicating that the crystal cell is mainly subjected to the thermal expansion. The slopes indicate that the average coefficients of thermal expansion are $\alpha_{\{10.0\}}^{\mathrm{bm}}=5.77 \times 10^{-6} \mathrm{~K}^{-1}$ and $\alpha_{\{00.2\}}^{\mathrm{bm}}=7.62 \times 10^{-6} \cdot \mathrm{K}^{-1}$ for the $\{10.0\}$ and $\{00.2\}$ reflections respectively. Typical literature values for a single crystal are $\alpha_{\mathrm{a}}^{\mathrm{lit}}=5.5 \times 10^{-6} \mathrm{~K}^{-1}$ and $\alpha_{\mathrm{c}}^{\mathrm{lit}}=10.8 \times$ $10^{-6} \mathrm{~K}^{-1}$ at $298 \mathrm{~K}$ [32]. The reduced anisotropy of coefficients can be understood by the intergranular constraining effect in a polycrystalline aggregate.

The lattice strains in the hydrided material are clearly nonlinear with temperature until all hydrides have been dissolved. The temperatures at which this transition occurs are different for heating or cooling, and they correspond to TSSd and TSSp. Consequently there is a clear hysteresis in the process. As a result of the non-linear contribution, the $\{10.0\}$ and $\{00.2\}$ reflections have experienced $30-50 \%$ more strain in the hydrided material than in the base material at $550{ }^{\circ} \mathrm{C}$.

The sources of change in lattice strain could be classified in two categories that we will call 'mechanical' and 'chemical' contributions. The difference lies in the scale at which the stress fields are applied on the lattice. In the present case, both effects can be superimposed. The first contribution results from an external stress field applied to a lattice: it deforms elastically and the interatomic distances vary accordingly which results in a diffraction peak shift. Because the atomic volume of the hydrides is $17 \%$ greater than that of the matrix, the formation of hydrides can generate tensile stresses in the matrix and compressive stresses in the precipitates. Thus during heating, dissolution of hydrides relieves the tensile stresses in the matrix, which is expected reduce the lattice expansion with temperature. Clearly, the trend observed in the present study is opposite. According to Yamanaka et al. [33], the thermal expansion coefficient of the hydrides is between 20 and $30 \times 10^{-6} \mathrm{~K}^{-1}$, i.e. $2-5$ times that of the matrix. Thus heating can generate misfit strains between the two phases and particularly 

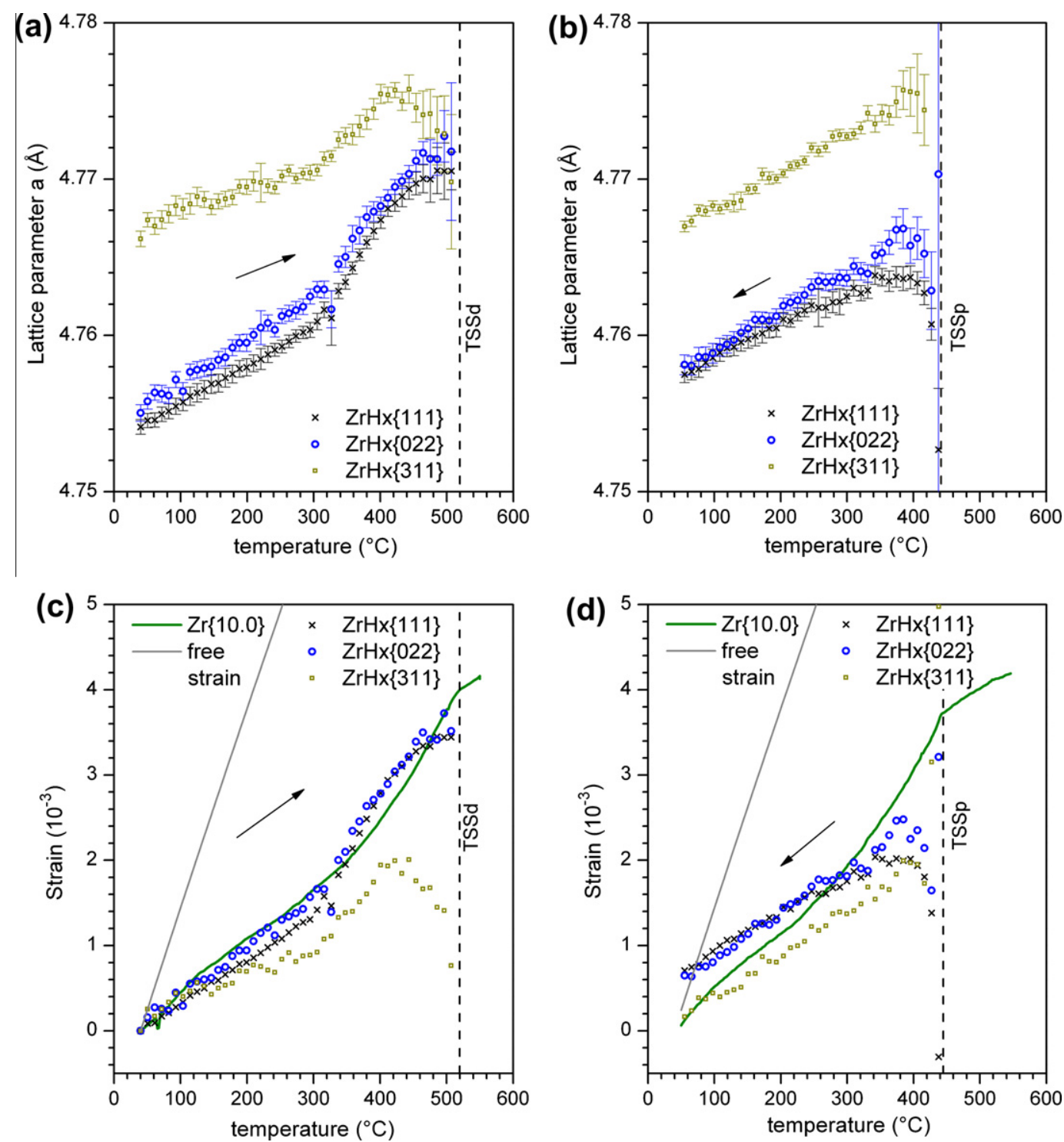

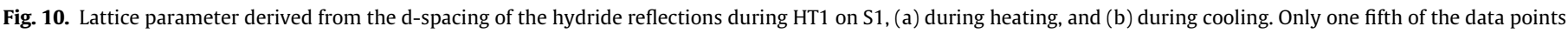

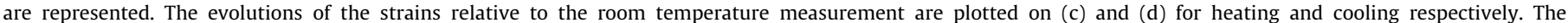
unconstrained (free) lattice strain is represented (from [1] and [35]). For reference, the strain free $\alpha-\{10.0\}$ is plotted as a grey line.

tensile stresses in the matrix. The trend observed experimentally is compatible with this effect.

The chemical contribution is for example a change in dissolved $\mathrm{H}$ content that can also cause a distortion of the lattice and affect the peak positions. In the present case let us consider the variations of hydrogen concentration in solid solution in the matrix. It has been shown in the literature that the insertion of a hydrogen atom in a tetrahedral site of an hcp cell leads to a volume increase of approximately $\Delta v_{0}=3 \AA^{3}$ [34]. Over the whole sampled volume (defined by the beam size and sample thickness), the average cell volume increase can be written as:

$\overline{\Delta v}=\frac{n_{\mathrm{Zr}}[\mathrm{H}]_{\mathrm{at}}}{1-[\mathrm{H}]_{\mathrm{at}}} \Delta v_{0}$

where $n_{\mathrm{Zr}}=2$ is the number of $\mathrm{Zr}$ atoms per cell, and $[\mathrm{H}]_{\text {at }}$ the molar hydrogen content in the solid solution $\alpha$.

The average cell volume increase can also be written as

$\overline{\Delta v}=\bar{v}-\bar{v}_{0}=\sqrt{3} / 2\left(\bar{a}^{2} \bar{c}-\bar{a}_{0}^{2} \bar{c}_{0}\right)$ where $\bar{a}$ and $\bar{c}$ are the mean cell parameters at a given $[\mathrm{H}]_{\mathrm{at}}$ and $\bar{a}_{0}$ and $\bar{c}_{0}$ for $[\mathrm{H}]_{\mathrm{at}}=0$ (i.e. at room temperature).

Assuming that the cell expansion is anisotropic, one can write that the average strain due to this cell distortion $\bar{\varepsilon}_{\mathrm{c}}^{\mathrm{d}}$ along the $\langle\mathrm{c}\rangle$ direction of the cell is proportional to the strain $\bar{\varepsilon}_{\mathrm{a}}^{\mathrm{d}}$ along the $\langle\mathrm{a}\rangle$ direction via a coefficient of anisotropy $K$. This parameter is set as a free parameter during the refinement of the model to fit the data. As a starting guess, $K$ was set to 1.9 which is a literature value for thermal anisotropy in $\mathrm{Zr}$ [32].

We can then write

$\overline{\Delta v}=\bar{v}_{0}\left(\left(\bar{\varepsilon}_{\mathrm{a}}^{\mathrm{d}}+1\right)^{2}\left(K \bar{\varepsilon}_{\mathrm{a}}^{\mathrm{d}}+1\right)-1\right)$

Since $\bar{\varepsilon}_{\mathrm{a}}^{\mathrm{d}} \ll 1$, this can be written as:

$\overline{\Delta v} \approx \bar{v}_{0}(2+K) \bar{\varepsilon}_{\mathrm{a}}^{\mathrm{d}}$

Finally, by combining Eqs. (8) and (11):

$\bar{\varepsilon}_{\mathrm{a}}^{\mathrm{d}}=\frac{n_{\mathrm{Zr}}[\mathrm{H}]_{\mathrm{at}}}{\left(1-[\mathrm{H}]_{\mathrm{at}}\right)(2+K) \bar{v}_{0}} \Delta v_{0}$ 
The molar hydrogen content in solid solution $[\mathrm{H}]_{\mathrm{at}}$ can easily be converted to a weight content $[\mathrm{H}]$ (in ppm). Since $[\mathrm{H}]$ has been determined experimentally (Fig. 3), it is thus possible to estimate $\bar{\varepsilon}_{\mathrm{a}}^{\mathrm{d}}$ and $\bar{\varepsilon}_{\mathrm{c}}^{\mathrm{d}}$ provided the coefficient of anisotropy of distortion $\mathrm{K}$ is known.

If we neglect the mechanical contributions previously mentioned, the total strain experienced by the lattice in the prismatic and basal directions can be decomposed in a thermal expansion term and a cell distortion term:

$\bar{\varepsilon}_{\mathrm{i}}^{\mathrm{tot}}=\alpha_{\mathrm{i}} T+\bar{\varepsilon}_{\mathrm{i}}^{\mathrm{d}}$

where $i$ represents the $\langle\mathrm{a}\rangle$ or $\langle\mathrm{c}\rangle$ direction and $\alpha_{\mathrm{i}}$ the associated thermal expansion coefficient (assumed constant).

These computed strains $\bar{\varepsilon}_{\mathrm{a}}^{\text {tot }}$ and $\bar{\varepsilon}_{\mathrm{c}}^{\text {tot }}$ can be directly compared to the measured $\{10.0\}$ and $\{00.2\}$ strains respectively. The identification of the coefficients $K$ and $\alpha i$ is performed by doing a least square refinement on the experimental data using the simplex optimisation method. The hydrogen content $[\mathrm{H}]$ was derived from the diffraction peak intensities. The agreement is good when using a coefficient of anisotropy $\mathrm{K}=1.47$, and thermal expansion coefficients $\alpha_{\mathrm{a}}^{\mathrm{fit}}=4.4 \times 10-6 \mathrm{~K}-1$ and $\alpha_{\mathrm{c}}^{\mathrm{fit}}=5.8 \times 10-6 \mathrm{~K}-1$ (Fig. 9b).

Since the fitted thermal expansion coefficients $\alpha_{\mathrm{a}}^{\mathrm{fit}}$ and $\alpha_{\mathrm{c}}^{\mathrm{fit}}$ are an average for a range of hydrogen concentrations between 0 and $475 \mathrm{ppm}$, they are slightly different than $\alpha_{\{10.0\}}^{\mathrm{bm}}$ and $\alpha_{\{00.2\}}^{\mathrm{bm}}$ measured on the non-hydrided base material. Moreover, the thermal expansion might be underestimated because the negative strain expected from the dissolution of the hydrides was neglected here.

\subsection{Lattice strains in the hydrides}

The $d$-spacings $d_{h k l}$ of the four observed hydride reflections were obtained from single peak fitting and converted into lattice parameter $a_{h k l}$ values using the relationship $a_{h k l}=$ $d_{h k l} \sqrt{h^{2}+k^{2}+l^{2}}$. The evolution of $a_{h k l}$ with temperature is plotted on Fig. 10a and b for heating and cooling respectively. For comparison with what happens in the matrix, the $d$-spacings were also converted to lattice strains. They are plotted on Fig. 10c and d along with the strain in the $\{10.0\}$ reflection of the solid solution phase (dark green line ${ }^{1}$ ). The plots also show in solid lines the expected lattice strains for an unconstrained hydride (called free strain), as derived from [35]. This expression accounts for the thermal expansion and the changes in $\mathrm{H}$ content in the matrix. This content was determined as a function of temperature from the phase diagram proposed by [1].

The initial lattice parameter is not the same for all the reflections, indicating that the hydrides are under strain at room temperature due to misfit stresses between the precipitates and the matrix. The measured values of a are also substantially lower than the room temperature free lattice parameter of $4.78 \AA$ [35] as could be expected for an inclusion highly constrained in compression. However, the diffraction setup used provides accurate results on the relative values of $d$-spacings and not on the absolute values. It is thus hazardous to draw conclusions from this.

During heating the lattice expands linearly and with a similar rate for all the reflections up to approximately $300{ }^{\circ} \mathrm{C}$. However the expansion rate is much lower than that of the free lattice. During this first stage, the strain evolution in the hydride is very close to that in the matrix. Above $300^{\circ} \mathrm{C}$, the lattice parameters increase more rapidly with temperature. At the moment, it is not clear to the authors as to why the $\{311\}_{\delta}$ reflection seems to relax above $420^{\circ} \mathrm{C}$ and more investigation is needed.

\footnotetext{
${ }^{1}$ For interpretation of color in Fig. 10, the reader is referred to the web version of this article.
}

Upon cooling and below TSSp, the lattices seem to undergo a rapid expansion, especially the $\{111\}$ reflection. However it cannot be ruled out that this could be a fitting artefact due to the very low intensities close to TSSp. From $370^{\circ} \mathrm{C}$ the $a_{h k l}$ decrease steadily. The values at room temperature are relatively close to those measured before the cycle. In terms of strain, the residuals are positive between 300 and $700 \mu \varepsilon$.

\section{Discussion}

\subsection{Hysteresis}

A number of authors have suggested that the hysteresis observed between dissolution and precipitation in hydrided zirconium could be solely due to kinetics [11]. The dwell experiments performed on sample S2 rebut this hypothesis: at the end of the dwell, equilibrium seems to be reached and the hydrogen content in solid solution is twice that obtained during heating for the same temperature. Instead the hypothesis developed by Leitch and Shi [17] seems more realistic: the combination of surface energy, elastic and plastic strains generated around the hydrides during their formation are responsible for the irreversible behaviour and the supersaturation of the solid solution. The results shown indicate that although kinetics effects partially contribute to the hysteresis, they are only of second order.

To understand better the contributions of elastic strain energy to the hysteresis one is tempted to look at the lattice strains in the matrix and the hydrides. The lattice strains in the matrix have already been analysed in the previous section and it seems clear that the observed evolutions with temperature are mainly due to thermal expansion, hydrogen content variations and anisotropy induced intergranular stresses. The influence of the misfit stresses with the precipitate inclusions seems of second order: because of the small volume fraction of hydrides the misfits affect a small portion of the matrix and the average overall strain is hardly affected.

The elastic strains measured in the hydrides could help understand the misfit stresses better (Fig. 10). It proves however more difficult to deconvoluate the factors contributing to the lattice parameters measured by diffraction than for the matrix. As it has been extensively discussed in the literature, the volume expansion resulting from hydride formation induces compressive stresses in the hydrides and tensile stresses in the matrix. During the initial stages of dissolution the lattice strains are a linear function of temperature. The slopes do not correspond to the theoretical thermal expansion of hydrides [33] but seem to be closer to the thermal expansion of the matrix. This could be explained by a highly compressive constrain effect applied by the matrix on the inclusions. It is consistent the literature where people consider that due to its lower density, hydrides should occupy $17 \%$ more volume than the matrix. From $300^{\circ} \mathrm{C}$, the strain in the $\{111\}$ and $\{022\}$ hydride reflections deviate significantly from linearity towards higher strains. Interestingly, those reflections behave very much like the free lattice. No clear explanation can be given at this stage but it is assumed that this relief could be related to the relative softness of $\alpha$ - $\mathrm{Zr}$ at temperatures above $300{ }^{\circ} \mathrm{C}$. It is also clear that the constraint exerted by the matrix is reduced due to what has been previously called the 'chemical' lattice expansion of the solid solution and resulting in a reduction of the misfit strain.

\subsection{Volume expansion}

Two mechanisms at the microscopic level can induce volume changes at the macroscopic level. It has been observed that the addition of hydrogen in a zirconium alloy can result in a macroscopic volume expansion at room temperature due to the formation of hydrides which have a low volumetric density [36]. On 
the other hand, the present work demonstrates that the dissolution of hydrogen induces a non-negligible volume expansion of the hcp zirconium cell which could be transferred to the macroscopic level. The two mechanisms are thus competing during thermal cycles at constant hydrogen content, since the former and the latter induce a volume expansion respectively upon cooling (formation of hydrides) and upon heating (dissolution of hydrogen). Brachet et al. [37] observed a significant volume expansion at the macroscopic level during heating. Their results also showed a non-linear expansion up to TSSd followed by a linear 'thermal expansion' type response above. It correlates very well, qualitatively at least, with the lattice expansion measured by diffraction (Fig. 9). The mechanism of hydrogen insertion in solid solution seems to be prevailing in the volume changes at the macroscopic level. The volume expansion due to the formation of hydrides is very localised and largely accommodated elastically and plastically by the surrounding matrix. This can explain why the transfer to the macroscopic level is attenuated.

\section{Conclusion}

In spite of the low diffraction peak intensity of the hydride phase in hydrided Zircaloy-4, it was possible to follow dissolution and precipitation of hydrides during slow and fast heating and cooling cycles by means of high-energy synchrotron X-ray diffraction. The present study has demonstrated the potential of using this technique for accurately following the phase transformation over a range of heating and cooling rates in situ. While the results presented here show good agreement with TSSd and TSSp data obtained by other authors using more conventional methods, the in situ work has also allowed to follow the gradual dissolution and precipitation/growth of hydrides in Zircaloy-4 throughout the temperature excursion and provided additional information about the lattice dilatation/strain evolution in both phases. The main findings can be summarised as follows:

- Continuous cooling at different rates and quench-hold heat treatments show that precipitation is rather fast at temperatures above $320^{\circ} \mathrm{C}$. The quantitative value, extracted from the dwell experiment at $400^{\circ} \mathrm{C}$, corroborates the results reported in $[10,26]$. However it must be emphasised again that the kinetics parameters reported here are upper bounds, which might be related to a slight time lag between the recorded and the sample temperatures. The precipitation kinetics under fast cooling conditions could not be tested in the low temperature regime due to the cooling limitations of the heating systems.

- It was deduced that kinetics contributes only marginally to the hysteresis observed between dissolution and precipitation.

- In the literature, the strains resulting from the volume misfit between hydrides and matrix are thought to be partly responsible for this supersaturation of the solid solution. For a better understanding, the lattice strains were studied in the matrix and the hydrides. It was evidenced by a simple calculation that the lattice strains observed in the matrix can be nearly solely explained by changes in matrix chemistry and the interphase elastic strains are certainly lost in the averaging inherent to the diffraction technique. The lattice strain evolution in the hydrides should provide more information regarding the misfit strains but is somewhat more complicated to interpret and further investigation is needed.

- The macroscopic volume expansion of hydrided Zircaloy-4 during heating seems primarily due to the insertion of hydrogen atoms in the $\alpha$ phase solid solution. The contraction resulting from the dissolution of the hydrides, which have a low volumetric density, could be negligible in comparison.
- As a final point, this paper emphasises and reminds the importance of considering the changes of solute content when studying strain by diffraction. Indeed one might be tempted to interpret the lattice variations as a result of mechanical stresses or thermal expansion only. It has been demonstrated that the introduction of atoms as small as hydrogen can induce a significant lattice strain in the solid solution of $\mathrm{Zr}$ and in the $\delta$ hydrides. Therefore care must be taken when using such data to draw conclusions on the stress states in hydrides or in the matrix.

\section{Acknowledgements}

We would like to thank F. Wehling from École Centrale Paris for the hydrogen charging of the plates. We are also grateful to the ESRF for provision of beamtime during proposals Nos. IN730 and MA802.

\section{References}

[1] E. Zuzek, J.P. Abriata, A. San-Martin, F.D. Manchester, H-ZR, in: F.D. Manchester (Ed.), Phase Diagrams of Binary Hydrogen Alloys, ASM International, 2000, pp. 309-322.

[2] O.N. Pierron, D.A. Koss, A.T. Motta, K.S. Chan, J. Nucl. Mater. 322 (2003) 21-35.

[3] IAEA, Delayed Hydride Cracking in Zirconium Alloys in Pressure Tube Nuclear Reactors, IAEA-TECDOC-1410, Vienna, 2004.

[4] M.P. Puls, J. Nucl. Mater. 393 (2009) 350-367.

[5] J.R. Santisteban, A. Steuwer, G. Domizzi, M.J. Peel, Powder Diffr. 24 (2009) 7276

[6] L. Lanzani, M. Ruch, J. Nucl. Mater. 324 (2004) 165-176.

[7] Z. Zhao, J.-P. Morniroli, A. Legris, A. Ambard, K. Khin, L. Legras, M. Blat-Yrieix, J. Microsc. 323 (2008) 410-421.

[8] J.H. Root, W.M. Small, D. Khatamian, O.T. Woo, Acta Mater. 51 (2003) 2041-2053.

[9] D.G. Westlake, Acta Metal. 12 (1964) 1373-1380.

[10] K. Une, S. Ishimoto, J. Nucl. Mater. 322 (2003) 66-72.

[11] J.H. Root, R.W.L. Fong, J. Nucl. Mater. 232 (1996) 75-85

[12] W.M. Small, J.H. Root, D. Khatamian, J. Nucl. Mater. 256 (1998) 102-107.

[13] S.R. MacEwen, C.E. Coleman, C.E. Ells, J. Faber, Acta Metal. 33 (1985) 753-757.

[14] M. Preuss, A. Steuwer, J. Romero, A-M. Alvarez, V. Grigoriev; SCIP Conference, 2008.

[15] K.B. Colas, A.T. Motta, J.D. Almer, M.R. Daymond, M. Kerr, A.D. Banchik, P. Vizcaino, J.R. Santisteban, Acta Mater. 58 (2010) 6575-6583.

[16] J.R. Santisteban, M.A. Vicente-Alvarez, P. Vizcaino, A.D. Banchik, J.D. Almer, Acta Mater. 58 (2010) 6609-6618.

[17] B.W. Leitch, S.-Q. Shi, Modelling Simul. Mater. Sci. Eng. 4 (1996) 281-292

[18] K. Linga Murty, I. Charit, Prog. Nucl. Energy 48 (2006) 325-359.

[19] J. Romero, M. Preuss, J. Quinta da Fonseca, Scripta Mater. 61 (2009) 399-402.

[20] J.E. Daniels, M. Drakopoulos, J. Synchrotron Rad. 16 (2009) 463-468.

[21] K.T. Erwin, O. Delaire, A.T. Motta, Y.S. Chu, D.C. Mancini, R.C. Birtcher, J. Nucl. Mater. 294 (2001) 299-304.

[22] X.Y. Meng, D.O. Northwood, J. Nucl. Mater. 132 (1985) 80

[23] A.A Coelho, Bruker AXS, 2008.

[24] V.F. Sears, S.A. Shelley, Acta Cryst. A 47 (1991) 441-446.

[25] A. McMinn, EC. Darby, J.S. Schofield, Zirconium in the nuclear industry, in: Twelfth International Symposium, Toronto, 2000.

[26] R. Tang, X. Yang, Int. J. Hydrogen Energy 34 (2009) 7269-7274.

[27] K. Une, S. Ishimoto, J. Nucl. Sci. Technol. 41 (2004) 949-952.

[28] G.F. Slattery, J. Inst. Metal. 95 (1967).

[29] B.F. Kammenzind, D.G. Franklin, H.R. Peters, W.J. Duffin, Hydrogen pickup and redistribution in alpha-annealed Zircaloy-4, in: E.R. Bradley, G.P. Sabol (Eds.), Zirconium in the Nuclear Industry - Eleventh International Symposium, ASTM STP 1295, ASTM International, West Conshohocken, PA, 1996.

[30] F. Xu, R.A. Holt, M.R. Daymond, Acta Mater. 56 (2008) 3672-3687.

[31] S.R. MacEwen, C. Tome, J. Faber, Acta Metal. 37 (1989) 979-989.

[32] J. Goldak, L.T. Lloyd, C.S. Barrett, Phys. Rev. 144 (1966) 478-484.

[33] S. Yamanaka, K. Yoshioka, M. Uno, M. Katsura, H. Anada, T. Matsuda, S. Kobayashi, J. Alloy. Compd. 293 (1999) 23-29.

[34] Y. Udagawa, M. Yamaguchi, H. Abe, N. Sekimura, T. Fuketa, Acta Mater. 58 (2010) 3927-3938.

[35] R.N. Singh, P. Ståhle, A.R. Massih, A.A. Shmakov, J. Alloy. Compd. 436 (2007) 150-154.

[36] M. Blat-Yrieix, A. Ambard, F. Foct, A. Miquet, S. Beguin, N. Cayet, Toward a better understanding of dimensional changes in Zircaloy-4: what is the impact induced by hydrides and oxide layer?, In: Zirconium in the Nuclear Industry: 15th International Symposium, ASTM STP 1505, West Conshohocken, PA, 2009.

[37] J.-C. Brachet, L. Portier, T. Forgeron, J. Hivroz, D. Hamon, T. Guilbert, T. Bredel, P. Yvon, J.-P. Mardon, P. Jacques, in: Thirteenth International Symposium on Zirconium in the Nuclear Industry, ASTM STP 1423, Annecy, France, 2002, pp. $673-701$.

[38] J.J. Kearns, J. Nucl. Mater. 22 (1967) 292-303. 